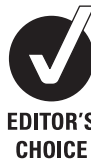

${ }^{1}$ University of the Witwatersrand Johannesburg, South Africa ${ }^{2}$ Schulthess Klinik and F-MARC (FIFA Medical Assessment and Research Center), Zurich, Switzerland

\section{Correspondence to} Professor Efraim Kramer, Faculty of Health Sciences, Office 10M12, Division of Emergency Medicine, University of the Witwatersrand, 7 York Road, Parktown, Johannesburg, 2123, South Africa; efraim.kramer@wits.ac.za

Accepted 19 April 2010

\title{
Review of the management of sudden cardiac arrest on the football field
}

\author{
Efraim Kramer, Jiri Dvorak, ${ }^{2}$ Walter Kloeck
}

\begin{abstract}
Football is the most popular sport on earth. When a young, fit popular player suddenly collapses and dies during play, the tragic event is frequently screened and publicised worldwide. The reported incidence of sudden cardiac arrest (SCA) varies from 1:65 000 to 1:200 000 athletes. A broad spectrum of cardiac and non-cardiac causes have been implicated, and regular precompetition medical assessments are recommended as a preventive measure. Immediate cardiopulmonary resuscitation and early defibrillation is the treatment for SCA. High success rates can be achieved if this is initiated promptly, preferably within seconds of the arrest. Trained medical responders must be allowed to respond, ideally with a defibrillator (manual or automated) in hand, to a player who suddenly and unexpectedly collapses and remains unresponsive on the field. Immediate defibrillation of a pulseless ventricular tachycardia or ventricular fibrillation, within 1 to $2 \mathrm{~min}$ of onset, has a successful cardioversion rate exceeding $90 \%$. Medical responders should be well trained and rehearsed in the recognition of SCA, including distractors such as seizures, myoclonic jerks and agonal (gasping) breathing. Prompt initiation of chest compressions on the field, together with early defibrillation, will result in many athletes' lives being saved by immediate implementation of these simple recommendations.
\end{abstract}

\section{INTRODUCTION}

Football (soccer), is the most popular sport on earth, with 260 million registered players ${ }^{1}$ representing 208 national football associations and a media viewership of billions. A number of football players reach the level of iconic stardom and are perceived by many young followers as role models to live up to. Therefore, when a young, fit, healthy, popular football player succumbs on the field of play to a sudden cardiac arrest (SCA), particularly when viewed on live television, it becomes a tragic event with catastrophic effects to the family, ${ }^{23}$ followers and to the football family worldwide. ${ }^{4}$ Such a tragic event is beyond most people's imagination or expectation, for it involves elite athletes who are at the pinnacle of health and success. The collapse and sudden cardiac death (SCD) of Miklós Fehrér, Marc-Vivien Foe, Daniel Jarque, Antonion Puerta and Phil $\bigcirc$ Donnel $^{5}$ are vivid examples of this tragic event.

\section{DEFINITIONS}

SCA can be defined as the sudden, unexpected cessation of cardiac output, usually of cardiac origin but not necessarily so, in a previously healthy appearing individual. SCD is defined as the sudden, unexpected natural death occurring within
$1 \mathrm{~h}$ of the onset of symptoms in a person who appears to be healthy or afflicted with a medical condition that is not considered fatal. ${ }^{67}$ An athlete, and hence a football player, is a person participating in an organised team sport that requires systematic training and regular competition against others, and that places a high premium on athletic excellence and achievement. ${ }^{89}$

\section{INCIDENCE}

The true incidence of SCA among footballers is not known, ${ }^{10}$ but can be predicted from available data in team-based athletes which reports an incidence of 1 in 65000 athletes to 1 in 200000 athletes, ${ }^{11-13}$ which in USA appears to equate to one SCA every 3 days $^{14}$ and is 2.5 times higher than in non-athletes. ${ }^{15}$ A prospective population-based study of SCD in young competitive athletes in the Vento Region of Italy indicated an incidence of SCD of 2.3 per 100000 athletes per year from all causes, and 2.1 per 100000 athletes per year from cardiovascular diseases. ${ }^{16}$

A further problem is the realisation that the reported figures are probably underestimated due to the absence of either postmortem results and/or mandatory reporting of SCA in sports in many countries including the USA. Whatever the true incidence may be internationally, there is no doubt that SCD is the leading cause of death in exercising young athletes ${ }^{11} 17$ and all efforts must be undertaken to prevent its occurrence by screening procedures such as the precompetition medical assessment, ${ }^{18} 19$ or when necessary, through efficient and effective emergency treatment. ${ }^{20}$

\section{CAUSES OF SCA}

A broad spectrum of cardiac and non-cardiac causes, both congenital and acquired, have been implicated in causing SCA in athletes. Similar to other estimated data concerning SCA in athletes, the exact numbers cannot be accurately quantified. However, from what is available from the USA and Italy, it appears that structural cardiac disease accounts for $60-95 \%$ of the causes of SCA, ${ }^{21-23}$ and mainly includes hypertrophic cardiomyopathy, arrythmogenic right ventricular dysplasia and congenital coronary artery anomalies in the under-35-year-old group, and coronary artery disease in the over-35-year-old group, all of which induce ventricular fibrillation (VF) as the main presenting rhythm in SCA. ${ }^{24}$ In the under16-year-old age group, commotio cordis (cardiac contusion) is thought to be responsible for up to $20 \%$ of SCAs. It is very uncommon after 21 years of age. ${ }^{25} 26$ Commotio cordis is the induction of VF during the vulnerable repolarisation period of online under the BMJ Journak unlocked scheme, see http:// bjsm.bmj.com/info/unlocked.dtl 
the myocardium due to a blunt, non-penetrating, usually high velocity, blow to the chest either from a small solid object, ${ }^{27}$ including a football ${ }^{28}$ or from contact with another player. Other cardiac causes of SCA include myocarditis, ruptured aortic aneurysm, aortic valve stenosis, mitral valve prolapse, dilated cardiomyopathy, drug-induced cardiac arrhythmias and the ion-channelopathies ${ }^{29}$ which include the long and short QT syndrome (caused by sodium or potassium ion channel genetic mutations), Brugada syndrome (defective sodium channel gene) and familial catecholaminergic polymorphic ventricular tachycardia ${ }^{30}$ (abnormal ryanodine receptor regulating calcium release). Non-cardiac causes of SCA include asthma, heat stroke, cerebral artery rupture and exertional rhabdomyolysis secondary to sickle cell trait.

\section{FIELD IDENTIFICATION OF SCA}

It is common during a football match for players to collapse on the field, mainly following contact with an opponent, for either a genuine or spurious ${ }^{31}$ injury (figure 1). The majority of these incidents are resolved with little therapeutic intervention from the team physician within a few minutes. According to the International Football Association Board Rules of the Game, if a player appears injured, the referee may stop play, approach the injured player and assess whether medical assistance is required. Once the referee has determined that medical assistance is required, they will then authorise one, or at most two doctors, to enter the field. ${ }^{32}$ This applies to the sideline medical stretcher bearers as well. A consequence of this rule, when response is required to a collapsed player, is some delay in waiting for the referee to first approach the injured player, determine the urgency of the situation and if needs be, summon the medical responders onto the field. ${ }^{33}$

If a player collapses to the ground as a consequence of bodily contact with an opposition player during competition, the referee is nearby and will visualise the incident and thus be in a position to respond to the injured player immediately. Were they to ascertain that the collapsed player is unconscious, they should summon medical assistance without delay. However, if the player collapses without having had any contact with either an opposition player or ball, particularly if it is out of sight of the referee, whose attention will be focused on the area of active play, this could substantially delay their awareness of the incident, and a much needed speedy response for life-saving assessment and treatment which is mandatory in SCA. ${ }^{34}$

From an emergency planning perspective, it would be highly advisable to revise the current Laws of the Game, to include 'an exception' that states that whenever a football player collapses on the field of play without there having being any contact with another player, the ball or physical object, this situation must be regarded as a SCA (until proven otherwise), with immediate response from the sideline (with a defibrillator) by the medical personnel on duty (team physician, physiotherapist, medical stretcher bearers and/or coach) without prior authorisation from the referee on the field, but with notification of the fourth official at the sideline.

Another major impediment to rapid recognition of SCA in athletes on the field of play, once they have collapsed, is the apparent signs of life that are evident in the first minutes after collapse. In over $50 \%$ of SCA in athletes, brief seizure-like activity or involuntary myoclonic jerk-like activity is present immediately after collapse. ${ }^{35}$ Thus, seizure activity may be the first obvious sign as to the cause of collapse to the responding referee or surrounding players nearby. Myoclonic movements after SCA are postulated to be due to oxygen deprivation to the brain as a result of the non-perfusing cardiac arrhythmia. To the unsuspecting responder, these seizure-like activities may appear as an epileptic seizure ${ }^{36}$ with consequent delay in critical initial management steps for SCA including cardiopulmonary resuscitation (CPR) and external defibrillation. To avoid these life-threatening delays in diagnosis and management after SCA, any athlete who collapses on the field of play and is unresponsive must be regarded as being in life-threatening cardiac arrest until it is proved otherwise. ${ }^{37}$ Accordingly, seizure-like activity must be regarded and taught as a sign of SCA and not as a standard tonic-clonic seizure per se, and training of CPR and automated external defibrillator (AED) use for potential first responders in sports environments is strongly recommended.

Another major obstacle to rapid recognition of SCA on the football field is the presence of abnormal or agonal breathing $^{38}$ in SCA patients during the first few minutes of arrest while the brain has sufficient oxygen supplies. Standard CPR training since $2005^{39}$ has emphasised that the apparent lack of normal breathing patterns is to be regarded as a sign of cardiac arrest and if present in an unresponsive person, equates to a diagnosis of cardiac arrest, with immediate activation of an emergency action plan and emergency medical services. In addition, the inability to adequately assess the presence or absence of a pulse has led to its detection being removed from layperson CPR training and is likewise de-emphasised in healthcare professionals.

Sportspersons and other potential first responders, must make every effort to respond expeditiously to the side of a collapsed footballer, particularly if no contact has occurred. If unresponsiveness is established, SCA should be regarded as being present, despite apparent signs of life, with activation of the emergency action plan which includes immediate CPR and defibrillator retrieval. It must be left up to experienced responding healthcare professionals to determine otherwise.

\section{ON-FIELD EMERGENCY MANAGEMENT}

The management of SCA has been described in many puvblications, most incorporating the 2005 International Liaison Committee on Resuscitation (ILCOR) guidelines. SCA is dominantly a cardiac arrythmogenic event with VF the dominant arrhythmia ${ }^{40}$ in $90 \%$ of cases. The treatment of this lethal condition is immediate external defibrillation, preceded, if defibrillation is not immediately available, by CPR. The single greatest factor affecting survival from SCA is the time interval from cardiac arrest to defibrillation. ${ }^{41}{ }^{42}$ Each minute of delay in initiating defibrillation after SCA leads to a $10 \%$ decrease in shock success. ${ }^{43}$ The internationally recommended target from the ILCOR ${ }^{39}$ from collapse-to-current (shock) is a3-5 $\mathrm{min}$. To achieve a rapid response practically involves prompt collapse recognition, rescuer activation, retrieval of the defibrillator, arrival at the patient's side, attachment of the defibrillator and arrhythmia recognition and defibrillator charge and delivery of the first shock. In 2005, the American College of Cardiology 36th Bethesda Conference recommended that every school hosting sports activities must have access to a defibrillator within 5 min of a patient's collapse. ${ }^{44}$ In 2007, an USA Inter-Association Task Force on Emergency Preparedness and Management of Sudden Cardiac Arrest in High School and College Athletic Programs recommended access to AEDs with a target goal of less than 3-5 min from collapse to current. ${ }^{45}$ Practically, these recommendations imply that for 


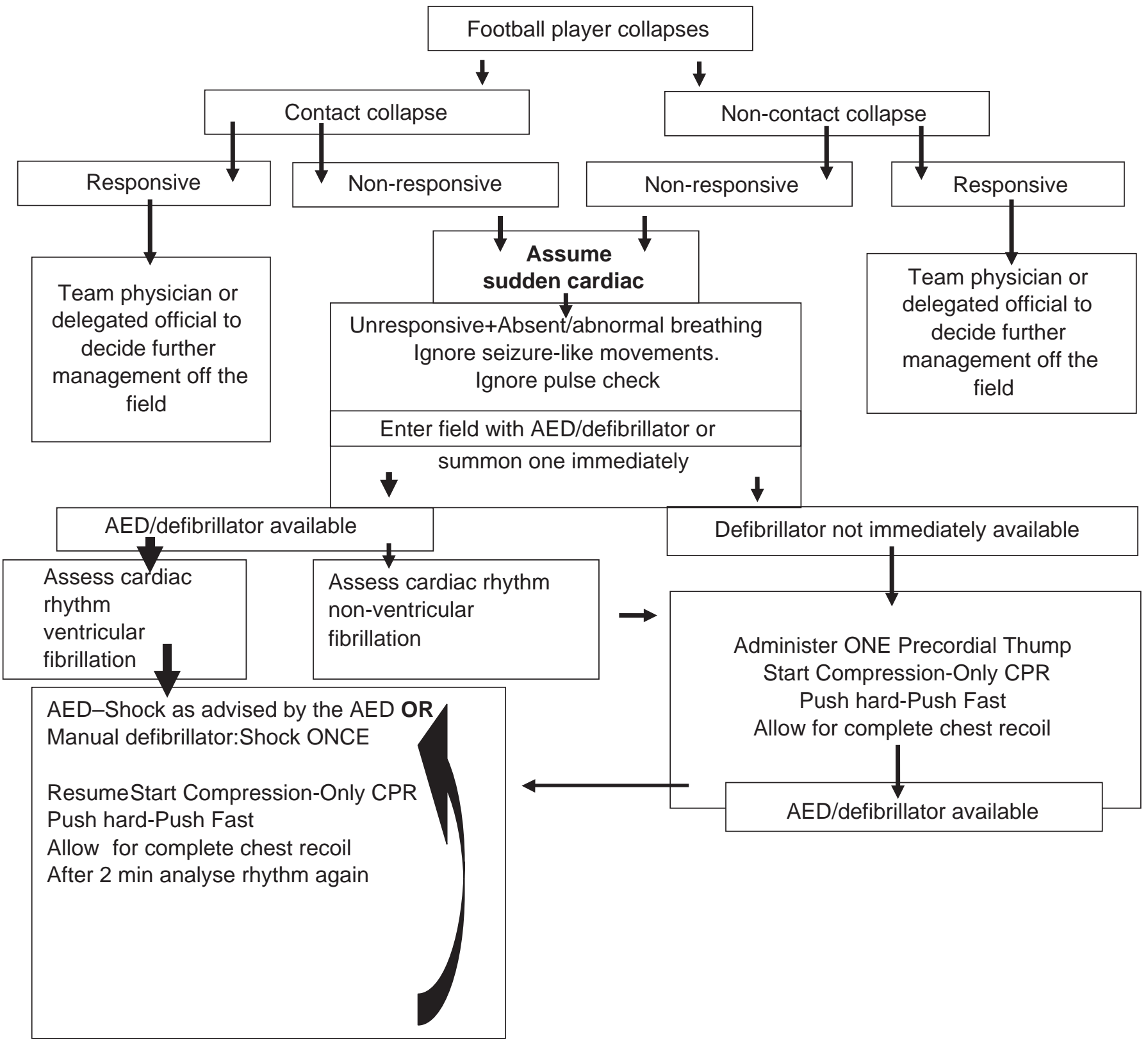

Figure 1 On field SCA management algorithm.

defibrillation to occur reliably within 3-5 min of activation, an on site defibrillator (AED) is required. ${ }^{4}$ Luiz et al ${ }^{46}$ described 13 witnessed cardiac arrests in spectators over a 6-7-year period in the Fritz-Walter Football Stadium that provided CPR within 2 min and defibrillation with 4 min resulting in a successful resuscitation rate (survival without neurological deficit) of $62 \%$. Conversely, an initial study by Drezner ${ }^{37}$ analysed a series of nine SCA cases among college athletes, of whom seven were in VF who received initial defibrillation shocks within $3.1 \mathrm{~min}$, yet only one of the nine sadly survived. Diagnostic studies in the lone survivor indicated no structural heart disease. It may therefore appear that that the 3-5 min 'timing goal' may be insufficient for SCA with VF occurring on the field of play, ${ }^{47} 48$ particularly those players who have underlying structural myocardial disease or commotio cordis as the underlying cause of VF. In an animal model of commotio cordis $^{49}$ in which external defibrillation was undertaken within 1-2 min of VF, successful resuscitation occurred in
$100 \%$ and $92 \%$ of animals, respectively. In the same experiment, only $46 \%$ of defibrillation shocks were successful after 4 min of VF, and after 6 min successful resuscitation decreased to $25 \%(p<0.0001)$. The success of early defibrillation in young athletes with SCA has been demonstrated in a recent report by Drezner et al showing a 64\% survival rate in high school athletes with SCA treated promptly by an on site defibrillator. ${ }^{35}$ Consequently, it must be recommended that in order to expeditiously ${ }^{3}$ defibrillate a player with SCA on the football field, one should strive for a 1-2 min collapse-toshock time goal, and it should be mandated that a defibrillator always be available at the sideline, either near the forth official at the midline, or with one of the medical stretcher teams, who should all be adequately trained in SCA recognition and on-field medical management as a matter of course.

If, for whatever logistical reason, there is at least one defibrillator available in a football stadium, whether housed in a medical centre or on-duty ambulance, it should be transferred 
to the side of the field during the football match, with its whereabouts known to all, including team physicians, team physiotherapists, venue medical officers, doping control medical officers, coaches and related medical personnel. The often observed practice of positioning a defibrillator in a medical centre inside the stadium for use in a collapsed spectator or inside a 'player' medical centre, without regard to positioning one at the field side requires serious review and revision. The current guidelines for medical services at Fédération Internationale de Football Association (FIFA) competitions by the FIFA require a defibrillator at the sideline. Emergency preparedness for SCA in spectators, especially at large football arenas, must also be considered. ${ }^{50}$

It must be appreciated that although an AED is considered basic life support and the external defibrillator of choice in developed countries, this may not be realistic in many countries where AEDs are not readily or absolutely available. In these situations, use of manual defibrillators, either monophasic, or if available, biphasic will be just as relevant and applicable, and may be a better choice, if the relevant training and experience is present. It is important in these situations that medical personnel have adequate knowledge of the specific defibrillator that they may be called upon to use, specifically the energy setting. It is recommended that the joule (J) setting for all monophasic defibrillators be set at $360 \mathrm{~J}$ initially, biphasic rectilinear defibrillators at $120 \mathrm{~J}$ and biphasic truncated exponential defibrillators at 150-200 J. In the event that the type of defibrillator and hence energy setting is not known to the operator, the suggested initial default setting is $200 \mathrm{~J} .{ }^{51}$

\section{IMMEDIATE PRECORDIAL THUMP}

Much transatlantic speculation and anecdotal banter continues to effect the performance, if at all, of a precordial thump in a witnessed cardiac arrest prior to initiation of CPR when a defibrillator is not immediately available. ${ }^{52-54}$ Maron $^{3}$ describe a case of a 14-year-old with SCA after a forceful collision with a teammate who was initially administered 'a forceful chest thump' by a physician bystander followed by standard CPR. The patient regained a spontaneous pulse after $90 \mathrm{~s}$ postincident. More recently, Madias et a ${ }^{155}$ found precordial thump in an experimental model to be effective for ventricular asystole but not for VF while the Resuscitation Council (UK) still has the precordial thump in its guidelines. ${ }^{56}$ In view of the absence of hard scientific data for or against the administration of a precordial thump in witnessed SCA and the slim chance that it may contribute towards a successful outcome, it is still to be recommended in those situations of SCA where a defibrillator is not immediately available, which unfortunately, internationally, may occur frequently in the football playing world.

\section{EXTERNAL CHEST COMPRESSION}

The initiation of CPR to a victim of SCA must be undertaken as speedily, safely, effectively and efficiently as practically possible, particularly if there is any delay in the immediate provision of a defibrillator. If the SCA has occurred after forceful contact of two players, it is possible that the victim of SCA may have fallen to the ground while unconscious, thus being unable to protect their spinal column from damage during impact with the ground. In such a case it must be assumed that an unstable cervical spine with potential injury is present and unnecessary uncontrolled movements during resuscitation should be avoided without compromising the resuscitation. If the victim begins to regurgitate (vomit) stomach contents during CPR, turning the player should be accomplished with due control and care. ${ }^{57} 58$ Since December 2005 , when the last revised set of recommendations for CPR and Emergency Cardiac Care from the ILCOR were published, the provision of standard CPR has encompassed the following guidelines:

- recommendation of a universal external chest compression-to-manual ventilation ratio of 30:2 for single rescuers for victims of SCA including adults, children and infants;

- provision of effective, efficient rhythmic external chest compressions at a rate of 100 compressions per minute with complete chest recoil after each compression'push hard, push fast';

- minimising interruptions in chest compression in order to maximise blood flow;

- external chest compressions must resume immediately after every defibrillation shock and continue for a minimum of $2 \mathrm{~min}$ before the rhythm analysis is repeated;

- CPR providers should consider changing roles with other providers after 2 min of external chest compression, to prevent fatigue induced inefficiencies in external chest compression;

- manual breathing via mouth-to-mouth with or without a barrier device or mask-to-mouth must be accomplished as effectively and efficiently as possible, ensuring that the chest rises with each breath, but without delaying external chest compressions.

Although there should be no shortage of persons available on and around a football field that can initiate effective and efficient CPR at international level competitions, this might not always be the case at practices or lower level competitions and in countries with less developed emergency medical services. Additionally, standard compression-ventilation CPR is regarded as a complex set of skills ${ }^{59}$ to initially muster and once acquired is prone to memory decline issues with time. The development and acceptance of external chest compression-only CPR (hands-only CPR, without ventilation) may be the answer to ensuring that immediate CPR will be effectively, efficiently and immediately undertaken on the football field during a SCA because of a number of practical and pedagogic advantages: ${ }^{60-65}$

- the only skill that is required is the performance of manual external compression (MEC) of the chest;

- active manual ventilation can be omitted for up to 10 min, as the football player is fully oxygenated before the onset of SCA;

- MEC is easily taught to any bystander and can be effectively administered with minimal supervision;

- minimal interruption with continuous external chest compression results in higher coronary perfusion pressures and greater blood flow;

- there are fewer objections to MEC from infectious or aesthetic concerns compared with standard CPR with mouth-to-mouth ventilation;

- the success rates with external chest compression-only CPR is at least similar to standard CPR.

It is recommended that chest compression-only CPR be considered as the most effective means of training large cadres of players, coaches and other likely responders in the football environment and that it be promoted as the initial method 
of CPR in the presence of a SCA, in conjunction with defibrillation. ${ }^{66} 67$ In South Africa, the Resuscitation Council of Southern Africa has endorsed the need to simplify the training of CPR, promoting a basic course named Simply CPR, ${ }^{68}$ where CPR represents:

- Call-for help if the victim is unresponsive;

- Push-on the chest if the victim is not breathing normally;

- Recharge - the heart with an external defibrillator or AED.

\section{PLANNING, EDUCATION AND TRAINING}

SCA will continue to occur on the football field, with and without preparticipation cardiac screening, even though efforts to broadly implement the latter is an important preventive measure. What cannot be totally prevented must therefore be managed when it does present. The medical management of SCA on the football field can only be effectively, efficiently and expeditiously managed if it is planned for beforehand with a known and distributed emergency action plan. This involves education and training of likely responders, availability of emergency equipment and regular updates and rehearsals. Simply CPR has been shown to adequately train classes of bystanders in $30 \mathrm{~min}$ by emphasising its three fundamental steps of call, push and recharge. It is of vital importance to instil in the football players, the physical trainers, coaches and football management personnel the basic understanding of a medical emergency action plan in the event of a life-threatening event during training or competition, and the invaluable part that each can contribute to a successful outcome. In the event of SCA in the football environment, multiple rescuers should be available to assist in CPR and defibrillator use. This means that multiple tasks can be undertaken simultaneously, especially if regular training is undertaken prior to the event. Failing that, it takes one trained person to adequately supervise a number of players or officials.

\section{CONCLUSION}

SCA is a catastrophic occurrence when it occurs because it may lead to the death of a young, fit, healthy popular football player. Preparticipation screening can do much to prevent such events, but it has limitations which ensure that SCA will continue to occur on the football field as well as in other sporting facilities. Nothing short of an established emergency action plan which is rehearsed and includes adequate numbers of motivated trained responders utilising appropriate life saving equipment ${ }^{69}$ and located in strategic positions during active training and competition, will afford the chance of a successful resuscitation of SCA.

Acknowledgements Grateful thanks are given to K Grimm and S Motaung for their assistance in preparation of the manuscript.

\section{Competing interests None.}

Provenance and peer review Not commissioned; externally peer reviewed.

\section{REFERENCES}

1. Dvorak J. 'Sudden Cardiac Death' makes the headline, but: 'Football for Health' is the message. Eur Heart J 2009;30:877-9.

2. Maron BJ. Sudden death in young athletes: lessons from the Hank Gathers affair. N Eng J Med 1993:329:55-7.

3. Maron BJ. Cardiovascular risks to young persons on the athletic field. Ann Intern Med 1998;129:379-86

4. Maron BJ. How should we screen competitive athletes for cardiovascular disease? Eur Heart J 2005;26:428-30.

\section{What is already known on this topic}

- Sudden cardiac arrest (SCA) is an infrequent event on the football field.

- Precompetition Medical Assessment is the recommended examination that may identify players at risk and thus prevent SCA.

- SCA on the football field is usually fatal if not managed expeditiously and efficiently using a defibrillator and effective cardiopulmonary resuscitation.

- An Emergency Action Plan is necessary to ensure a speedy response to a collapsed football player.

\section{What this study adds}

- The necessity to place a defibrillator on the sideline of the football field during a match.

- Hands-only cardiopulmonary resuscitation (CPR) is recommended as the initial on-field CPR technique for first responders, until defibrillation can be undertaken.

- Defibrillation, from potential hypertrophic cardiomyopathy, may require defibrillation sooner than the usual $3-5$ min to be successful.

- A player who collapses without contact must be considered a cardiac arrest until proved otherwise.

- All members of a football team should be trained in at least hands-only CPR.

5. Jarque, Foe, Feher, Puerto, O'Donnel: Soccer's Sudden Cardiac Arrest Deaths. http://www.cardiacscience.com/blog/2009/08/jarque-foe-fehrer-soccer-suddencardiac-arrest/ (Accessed 23 December 2009).

6. Pigozzi F, Rizzo M. Sudden death in competitive athletes. Clin Sports Med 2008;27:153-81, ix.

7. Özdemir Ç, Saka T, Asil H, et al. Soccer related sudden deaths in Turkey. J Sport SciMed 2008:7:292-8.

8. Maron BJ, Thompson PD, Puffer JC, et al. Cardiovascular preparticipation screening of competitive athletes. A statement for health professionals from the Sudden Death Committee (clinical cardiology) and Congenital Cardiac Defects Committee (cardiovascular disease in the young), American Heart Association. Circulation 1996:94:850-6.

9. Bethesda Conference: recommendations for determining eligibility for competition in athletes with cardiovascular abnormalities. Med Sci Sports Exerc 1994;26:S223-83

10. Bille K, Figueiras D, Schamasch P, et al. Sudden cardiac death in athletes: the Lausanne Recommendations. Eur J Cardiovasc Prev Rehabil 2006;13:859-75.

11. van Camp SP, Bloor CM, Mueller FO, et al. Nontraumatic sports death in high school and college athletes. Med Sci Sports Exerc 1995;27:641-7.

12. Drezner JA, Rogers KJ, Zimmer RR, et al. Use of automated external defibrillators at NCAA Division I universities. Med Sci Sports Exerc 2005;37:1487-92.

13. Hillis WS, McIntyre PD, Maclean J, et al. ABC of sports medicine. Sudden death in sport. BMJ 1994;309:657-60.

14. Harmon KG, Drezner JA. Update on sideline and event preparation for management of sudden cardiac arrest in athletes. Curr Sports Med Rep 2007;6:170-6.

15. Corrado D, Basso C, Rizzoli G, et al. Does sports activity enhance the risk of sudden death in adolescents and young adults? J Am Coll Cardiol 2003:42:1959-63.

16. Corrado D, Pelliccia A, Bjornstad HH, et al. Cardiovascular preparticipation screening of young competitive athletes for prevention of sudden death: proposa for a common European protocol. Consensus Statement of the Study Group of Sport Cardiology of the Working Group of Cardiac Rehabilitation and Exercise 
Physiology and the Working Group of Myocardial and Pericardial Diseases of the European Society of Cardiology. Eur Heart J 2005;26:516-24.

17. Maron BJ. Sudden death in young athletes. N Engl J Med 2003;349:1064-75.

18. Thünenkötter T, Schmied C, Grimm K, et al. Precompetition cardiac assessment of football players participating in the 2006 FIFA World Cup Germany. Clin J Sport Med 2009;19:322-5

19. Maron BJ, Thompson PD, Ackerman MJ, et al:; American Heart Association. Recommendations and considerations related to preparticipation screening for cardiovascular abnormalities in competitive athletes: 2007 update: a scientific statement from the American Heart Association Council on Nutrition, Physical Activity, and Metabolism: endorsed by the American College of Cardiology Foundation. Circulation 2007:115:1643-455.

20. Strasburger JF, Maron BJ. Commotion cordis. N Eng J Med 2002;347:1248.

21. Maron BJ, Epstein SE, Roberts WC. Causes of sudden death in competitive athletes. J Am Coll Cardiol 1986;7:204-14.

22. Corrado D, Basso C, Schiavon M, et al. Screening for hypertrophic cardiomyopathy in young athletes. N Eng/ J Med 1998;339:364-9.

23. Turk EE, Riedel A, Püeschel K. Natural and traumatic sports-related fatalities: a 10-year retrospective study. Br J Sports Med 2008;42:604-8; discussion 608.

24. Thiene G. Football stadium defibrillators for cardiac arrest. Eur Heart J 2009;30:743-9.

25. Weinstock J, Maron BJ, Song C, et al. Failure of commercially available chest wall protectors to prevent sudden cardiac death induced by chest wall blows in an experimental model of commotio cordis. Pediatrics 2006:117:e656-62.

26. Priori SG, Aliot E, Blømstrom-Lundqvist C, et al.; European Society of Cardiology. Task force on sudden cardiac death. Europace 2002;4:3-18

27. Abrunzo TJ. Commotio cordis - the single most common cause of traumatic death in youth baseball. Am J of Dis Child 1991;145:1279-82.

28. Thakore S, Johnstone $\mathrm{M}$, Rogena $\mathrm{E}$, et al. Non-penetrating chests blows and sudden cardiac arrest in the young. EMJ 2000;17:421-2.

29. Corrado D, Basso C, Thiene G. Is it time to include ion channel diseases among cardiomyopathies? J Electrocardiol 2005;38:81-7.

30. Arias MA, Fernández-Guerrero JC, Herrador J, et al. Catecholaminergic polymorphic ventricular tachycardia as a cause of sudden death in athletes. Am J Emerg Med 2006:24:253-4.

31. Decisions of the International Football Association Board: Law 12 Decision 5. http://www.fifa.com/flash/lotg/football/en/Laws12_06.htm (Accessed 24 December 2009).

32. International Football Association Board. Laws of the Game 2009/2010. Zurich, Switzerland: Fédération Internationale de Football Association, 2009:67.

33. S.E.R.I.O.U.S. method for dealing with Injuries. Referees Association. Available at: http://footballreferee.org/better_refereeing_injury.php (Accessed 24 December 2009).

34. Maron BJ, Strasburger JF, Kugler JD, et al. Survival following blunt chest impactinduced cardiac arrest during sports activities in young athletes. Am J Cardiol 1997; 79:840-1.

35. Drezner JA, Rao AL, Heistand J, et al. Effectiveness of emergency response planning for sudden cardiac arrest in United States high schools with automated external defibrillators. Circulation 2009;120:518-25.

36. Hauff SR, Rea TD, Culley LL, et al. Factors impeding dispatcher-assisted telephone cardiopulmonary resuscitation. Ann Emerg Med 2003:42:731-7.

37. Drezner JA, Rogers KJ. Sudden cardiac arrest in intercollegiate athletes: detailed analysis and outcomes of resuscitation in nine cases. Heart Rhythm 2006; $3: 755-9$

38. Ruppert M, Reith MW, Widmann JH, et al. Checking for breathing: evaluation of the diagnostic capability of emergency medical services personnel, physicians, medical students, and medical laypersons. Ann Emerg Med 1999;34:720-9.

39. The 2005 International Consensus on cardiopulmonary resuscitation (CPR) and emergency cardiovascular care (ECC) science with treatment recommendations. Circulation 2005;112(Suppl 22):III5-24.

40. Maron BJ, Pelliccia A. The heart of trained athletes: cardiac remodeling and the risks of sports, including sudden death. Circulation 2006;114:1633-44.

41. Hazinski MF, Markenson D, Neish S, et al. Response to cardiac arrest and selected life-threatening emergencies: the medical emergency response plan for schools. A statement for healthcare providers, policymakers, school administrators, and community leaders. Circulation 2004;109:278-91.

42. Drezner JA. Preparing for sudden cardiac arrest-the essential role of automated external defibrillators in athletic medicine: a critical review. Br J Sports Med 2009:43:702-7.

43. Simons SM, Berry J. Preventing sudden death: the role of automated defibrillators. Physician Sportsmed 1993;21:53-9.

44. Myerburg RJ, Estes NA 3rd, Fontaine JM, et al. Task Force 10: automated external defibrillators. J Am Coll Cardiol 2005;45:1369-71.
45. Drezner JA, Courson RW, Roberts W0, et al. Inter-association task force recommendations on emergency preparedness and management of sudden cardiac arrest in high school and college athletic programs: a consensus statement. Clin J Sport Med 2007;17:87-103.

46. Luiz T, Kumpch M, Metzger M, et al. Management of cardiac arrest in a German soccer stadium. Structural, process and outcome quality. Anaesthesist 2005;54:914-22

47. Maron BJ, Gohman TE, Kyle SB, et al. Clinical profile and spectrum of commotio cordis. JAMA 2002;287:1142-6.

48. Maron BJ, Wentzel DC, Zenovich AG, et al. Death in a young athlete due to commotio cordis despite prompt external defibrillation. Heart Rhythm 2005; $:$ :991-3.

49. Link MS, Maron BJ, Stickney RE, et al. Automated external defibrillator arrhythmia detection in a model of cardiac arrest due to commotio cordis. J Cardiovasc Electrophysiol 2003;14:83-7.

50. Borjesson M, Dugmore D, Mellwig KP, et al. Time for action regarding cardiovascular emergency care at sports arenas: a lesson from the arena study. Eur Heart J 2010 (In Press)

51. 2005 International Consensus on cardiopulmonary resuscitation and emergency cardiac care science with treatment recommendations. Part 3: defibrillation. Circulation 2005;112:III17-24.

52. Scherf $\mathbf{D}$, Bornemann C. Thumping of the precordium in ventricular standstill. Am $J$ Cardiol 1960:5:30-40.

53. Miller J, Tresch D, Horwitz L, et al. The precordial thump. Ann Emerg Med 1984:13:791-4.

54. Kloeck W, Cummins RO, Chamberlain D, et al. The universal advanced life support algorithm: an advisory statement from the Advanced Life Support Working Group of the International Liaison Committee on Resuscitation. Circulation 1997;95:2180-2

55. Madias C, Maron BJ, Alsheikh-Ali AA, et al. Precordial thump for cardiac arrest is effective for asystole but not for ventricular fibrillation. Heart Rhythm 2009;6:1495-500.

56. Resuscitation Guidelines 2005. Resuscitation Council (UK). http://www.resus. org.uk/pages/als.pdf (Accessed 27 December 2009).

57. Skolnik NS, Barret B. Clinical guidelines for family physicians: management of sudden cardiac arrest in young athletes. J Athl Train 2007:42:143-58.

58. Kerber RE, Becker LB, Bourland JD, et al. Automatic external defibrillators for public access defibrillation: recommendations for specifying and reporting arrhythmia analysis algorithm performance, incorporating new waveforms, and enhancing safety. A statement for health professionals from the American Heart Association Task Force on Automatic External Defibrillation, Subcommittee on AED Safety and Efficacy. Circulation 1997;95:1677-82.

59. Flint LS Jr, Billi JE, Kelly K, et al. Education in adult basic life support training programs. Ann Emerg Med 1993;22:468-74.

60. Berg RA, Kern KB, Sanders AB, et al. Bystander cardiopulmonary resuscitation. Is ventilation necessary? Circulation 1993;88:1907-15.

61. Berg RA, Sanders AB, Kern KB, et al. Adverse hemodynamic effects of interrupting chest compressions for rescue breathing during cardiopulmonary resuscitation for ventricular fibrillation cardiac arrest. Circulation 2001; 104:2465-70

62. Berg RA, Kern KB, Hilwig RW, et al. Assisted ventilation during 'bystander' CPR in a swine acute myocardial infarction model does not improve outcome. Circulation 1997;96:4364-71.

63. Steen PA. Does active rescuer ventilation have a place during basic cardiopulmonary resuscitation? Circulation 2007;116:2514-16.

64. Ewy GA. Continuous-chest-compression cardiopulmonary resuscitation for cardiac arrest. Circulation 2007;116:2894-6.

65. Bohm K, Rosenquist M, Herlitz J, et al. Survival is similar after standard treatment and chest compression only in out-of-hospital bystander cardiopulmonary resuscitation. Circulation 2007;116:2980-12.

66. Sayre MR, Berg RA, Cave DM, et al. Hands-only (compression-only) cardiopulmonary resuscitation: a call to action for bystander response to adults who experience out-of-hospital sudden cardiac arrest: a science advisory for the public from the american heart association emergency cardiovascular care committee. Circulation 2008:117:2162-7.

67. American Heart Association. Hands-Only CPR. http://handsonlycpr.org/ (Accessed 27 December 2009).

68. Resuscitation Council of Southern Africa. 'Plea to the South African public: It's time to learn CPR!.' 2009. http://emssa.org.za/plea-to-the-south-african-public\%E2\%80\%93-it\%E2\%80\%99s-time-to-learn-cpr/ (Accessed 27 December 2009)

69. Herring SA, Bergfeld J, Boyd J, et al. Sideline Preparedness for the Team Physician: A Consensus Statement. http://www.acsm.org/AM/Template.cfm ? Section $=$ Clinicians 1 \&Template $=/ \mathrm{CM} /$ ContentDisplay.cfm\&ContentID $=8066$ (Accessed 27 December 2009). 